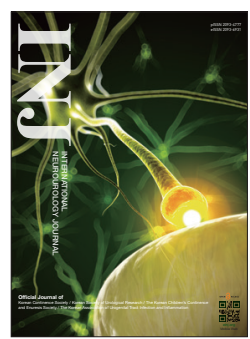

\title{
Urodynamic and Bladder Diary Factors Predict Overactive Bladder- wet in Women: A Comparison With Overactive Bladder-dry
}

\author{
Sheng-Mou Hsiao ${ }^{1,2,3, *}$, Pei-Chi Wu ${ }^{2, *}$, Ting-Chen Chang ${ }^{2}$, Chi-Hau Chen², Ho-Hsiung Lin ${ }^{1,2}$ \\ ${ }^{1}$ Department of Obstetrics and Gynecology, Far Eastern Memorial Hospital, Banqiao, New Taipei, Taiwan \\ ${ }^{2}$ Department of Obstetrics and Gynecology, National Taiwan University College of Medicine and Hospital, Taipei, Taiwan \\ ${ }^{3}$ Graduate School of Biotechnology and Bioengineering, Yuan Ze University, Taoyuan, Taiwan
}

Purpose: To identify factors predicting the presence of overactive bladder syndrome (OAB)-wet, compared with OAB-dry. Methods: Between September 2007 and September 2013, the medical records of 623 women with OAB who completed a 3 -day bladder diary and underwent urodynamic studies in a medical center were retrospectively reviewed. OAB-wet was diagnosed in patients who complained of at least one episode of urgency incontinence in the previous month; otherwise, OABdry was diagnosed. Multivariable logistic regression analysis was used to predict the presence of $O A B$-wet.

Results: Age (odds ratio [OR], 1.05; $\mathrm{P}<0.001)$, maximal flow rate (Qmax) $(\mathrm{OR}, 1.06 ; \mathrm{P}<0.001)$, voided volume (OR, 0.996; $\mathrm{P}=0.001)$, detrusor pressure at maximal flow rate (PdetQmax) $(\mathrm{OR}, 1.02 ; \mathrm{P}=0.003)$, urgency episodes $(\mathrm{OR}, 1.04 ; \mathrm{P}<0.001)$ and urodynamic stress incontinence $(\mathrm{OR}, 1.78 ; \mathrm{P}=0.01)$ were independent predictors for the presence of $\mathrm{OAB}$-wet vs. $\mathrm{OAB}$ dry. If we use bladder contractility index as a variable for multivariable logistic regression analysis, bladder contractility index (OR, 1.012; $\mathrm{P}<0.001$ ) become an independent predictor for $\mathrm{OAB}$-wet.

Conclusions: A smaller bladder capacity and more frequent urgency episodes were predictors of OAB-wet, and the above findings indicate that $\mathrm{OAB}$-wet and $\mathrm{OAB}$-dry might be a continuum of OAB. Old age, high Qmax, high PdetQmax and urodynamic stress incontinence were also predictors for $\mathrm{OAB}$-wet, and the above results reveal that $\mathrm{OAB}$-wet and $\mathrm{OAB}$-dry have partially different clinical and urodynamic features. Further studies might be performed to elucidate whether different treatment strategies between $\mathrm{OAB}-\mathrm{dry}$ and $\mathrm{OAB}-$ wet can improve treatment efficacy.

Keywords: Overactiveurinary bladder; Urodynamics; Urgeurinary incontinence

- Research Ethics: This study was approved by the Research Ethics Committee in National Taiwan University Hospital (approval number: 201404012RINC). Besides, this study has been registered at ClinicalTrials.gov (NCT03560778). The informed consents were not obtained due to that this is a retrospective study and the data were analyzed anonymously, and the National Taiwan University Hospital Research Ethics Committee waived the need for informed consent form the participants.

- Conflict of Interest: No potential conflict of interest relevant to this article was reported.

\section{INTRODUCTION}

The definition of overactive bladder syndrome $(\mathrm{OAB})$ is urinary urgency, with or without urgency urinary incontinence, which is usually accompanied by urinary frequency and nocturia in the absence of urinary tract infection or other obvious pathologies [1].

$\mathrm{OAB}$ can be subclassified as OAB-dry or OAB-wet [2], with
Corresponding author: Ho-Hsiung Lin (ib https://orcid.org/0000-0002-0511-9321 Department of Obstetrics and Gynecology, National Taiwan University College of Medicine and Hospital, No. 8, Chung-Shan South Road, Taipei 100, Taiwan E-mail: hhlin@ntuh.gov.tw / Tel: +886-2-23123456 (ext. 71557) / Fax: +886-2-23934197 Submitted: October 6, 2018 / Accepted after revision: February 19, 2019

*Sheng-Mou Hsiao and Pei-Chi Wu contributed equally to this work as co-first authors.
(C) (1) This is an Open Access article distributed under the terms of the Creative Commons Attribution Non-Commercial License (http://creativecommons.org/licenses/by-nc/4.0/) which permits unrestricted non-commercial use, distribution, and reproduction in any medium, provided the original work is properly cited. 
an approximate ratio of 2 to 1 [3], and the prevalence of OABwet increases with advancing age [4]. However, the underlying pathophysiology of OAB-dry vs. OAB-wet may be different. Kuo et al. [5] reported that urinary nerve growth factor levels are increased in OAB-wet but not OAB-dry. Hsiao et al. [6] reported that $\mathrm{C}$-reactive protein levels are increased in $\mathrm{OAB}$-wet. Hashim and Abrams [7] reported 44\% of women with OAB-dry had detrusor overactivity (DO), while $58 \%$ of women with OAB-wet had DO. Al-Ghazo et al. [8] also reported $61 \%$ of women with OAB-dry had DO, while $69.8 \%$ of women with OAB-wet had DO. It has been reported that many patients labeled as OAB-dry may actually be mild $\mathrm{OAB}$-wet [2].

Currently, treatments for OAB-dry vs. OAB-wet patients are nearly the same [9]. Nonetheless, for intravesical injection of onabotulinumtoxin $\mathrm{A}, \mathrm{OAB}$-wet patients are associated better therapeutic efficacy [10]. Balzarro et al. [11] also confirmed the efficacy of intravesical injection of onabotulinumtoxinA for treatment of women with OAB-wet. An Urgency Severity Scale score of 4 is $\mathrm{OAB}$-wet, and it was reported that $\mathrm{OAB}$ patients with high Urgency Severity Scale score were associated with better therapeutic efficacy after solifenacin treatment [12,13].

Different underlying pathophysiologies may benefit from different treatments. We are interested in whether there is a different underlying pathophysiology in OAB-dry vs. OAB-wet. Comparison of clinical and urodynamic variables between OAB-dry and $\mathrm{OAB}$-wet might be helpful for understanding the underlying pathophysiology. Thus, the aim of this study was to identify clinical and urodynamic factors predicting $\mathrm{OAB}$-wet, compared with OAB-dry.

\section{MATERIALS AND METHODS}

Between September 2007 and September 2013, the medical records of consecutive 623 women with OAB who completed a 3-day bladder diary and underwent urodynamic studies at the urogynecologic outpatient clinics of the Department of Obstetrics and Gynecology of a medical center were retrospectively reviewed. OAB was defined as the presence of urinary urgency, with or without urgency incontinence, which is usually accompanied by urinary frequency and nocturia [1]. This study was approved by the Research Ethics Committee in our hospital. Besides, this study has been registered at ClinicalTrials.gov.

The following inclusion criteria were used: (1) women at least 18 years old, who had at least a 3-month history of $\mathrm{OAB}$ symptoms, including urgency, urinary frequency, nocturia, or urge incontinence and (2) an average of $\geq 8$ micturitions in 24 hours $[14,15]$. The exclusion criteria included dominant symptoms with stress urinary incontinence, regular urethral catheterization or intermittent self-catheterization, urinary tract infection or chronic inflammation in the previous 2 weeks, bladder calculus, neurogenic bladder due to radical hysterectomy or injury of central nervous system, and a history of pelvic radiotherapy or a preexisting malignant pelvic tumor. In the study of Stewart et al. [16], OAB-dry was defined as patients who had $\geq 4$ urgency episodes in the past 4 weeks; and OAB-wet was defined as patients who complained of $\geq 3$ urgency incontinence episodes in the past 4 weeks. However, in our study, OABwet was diagnosed in patients who complained of at least one episode of urgency incontinence in the previous month; otherwise, OAB-dry was diagnosed.

The medical history, including information such as age and parity, was reviewed for each patient. The urodynamic assessment included uroflowmetry, filling cystometry with $35^{\circ} \mathrm{C}$ distilled water at a rate of $60 \mathrm{~mL} / \mathrm{sec}$, a pressure flow study, and the stress urethral pressure profile with patient in sitting position [17]. Additionally, a 20-minute pad test for each woman was performed [18,19]. DO was defined as evidence of spontaneous detrusor contractions occurring during bladder filling or an uninhibited detrusor contraction occurring at a cystometric capacity that usually results in voiding [20]. If patients had a strong desire to void at a volume less than $300 \mathrm{~mL}$, they were considered to have bladder oversensitivity [21]. Functional bladder outlet obstruction (BOO) was defined as uroflowmetry results $<15-\mathrm{mL} / \mathrm{sec}$ maximal flow rate (Qmax) and $>20-\mathrm{cm}$ $\mathrm{H}_{2} \mathrm{O}$ detrusor pressure at maximal flow rate (PdetQmax) measured via voiding cystometry and without a known anatomic cause of obstruction [22,23].

Multichannel urodynamic equipment (Life-Tech, Houston, TX, USA) with computer analysis and Urovision (Urolab Janus System V, Houston) was used. All terminology conformed to the standards recommended by the International Continence Society and Urodynamic Society [1]. All procedures were performed by an experienced technician, and the data were interpreted by a single observer to avoid interobserver variability.

STATA ver. 11.0 (Stata Corp., College Station, TX, USA) was used for statistical analyses. The chi-square test and Wilcoxon rank-sum test were used as appropriate. A P-value of less than 0.05 was considered statistically significant. A multivariable logistic regression analysis was performed using variables that had a P-value $<0.05$ from the univariate analysis [24]. 


\section{RESULTS}

One hundred twenty-seven women with OAB-wet and 496 women with $\mathrm{OAB}$-dry were enrolled in this study. Comparisons of age, parity, pad weights, and urodynamic and bladder diary parameters between the $\mathrm{OAB}$-wet and $\mathrm{OAB}$-dry groups are shown in Tables 1 and 2. Age and parity were significantly different between the OAB-wet and OAB-dry groups (Table 1). After adjusting for age and parity, we found that Qmax, voided volume, PdetQmax, urodynamic stress incontinence (USI), pad weight, urgency episodes, incontinence episodes, and bladder contractility index (i.e., $=$ PdetQmax $+5 \times$ Qmax) [25] were significantly different between the $\mathrm{OAB}$-wet and $\mathrm{OAB}$-dry groups (Tables 1,2).

Because pad weight was highly correlated to USI (Spearman rho $=0.88, \mathrm{P}<0.0001$ ), pad weight was not included in the multivariable analysis (Table 2). In addition, incontinence episodes $>0$ predicted $\mathrm{OAB}$-wet perfectly, therefore, we excluded the variable "incontinence episodes" in the multivariable analysis (Table 2). In model 1, using age, parity and the other statistically significant adjusted variables shown in Tables 1 and 2, a multivariable logistic regression was performed to predict $\mathrm{OAB}$-wet (Table 3). Age (odds ratio [OR],1.05; $\mathrm{P}<0.001$ ), Qmax (OR, 1.06; $\mathrm{P}<0.001$ ), voided volume (OR, 0.996; $\mathrm{P}=0.001$ ), Pdet $\mathrm{Q}-$ $\max (\mathrm{OR}, 1.02 ; \mathrm{P}=0.003)$, USI (OR, $1.78 ; \mathrm{P}=0.01)$, and urgency episodes $(\mathrm{OR}, 1.04 ; \mathrm{P}<0.001)$ were independent predictors for OAB-wet vs. OAB-dry (Table 3). In model 2, bladder contractility index was included as a variable for multivariable logistic regression to predict $\mathrm{OAB}$-wet, instead of using Qmax and PdetQmax as variables (Table 3); bladder contractility in-

Table 1. Comparisons of the urodynamic parameters between the OAB-wet and OAB-dry groups $(\mathrm{n}=623)$

\begin{tabular}{|c|c|c|c|c|c|}
\hline Variable & $\begin{array}{l}\text { OAB-wet } \\
(\mathrm{n}=127)\end{array}$ & $\begin{array}{l}\text { OAB-dry } \\
(\mathrm{n}=496)\end{array}$ & P-value ${ }^{a)}$ & $\begin{array}{c}\text { Coefficient or OR } \\
\left.(95 \% \text { CI }) \text { of OAB-wet }{ }^{\mathrm{b}}\right)\end{array}$ & P-value ${ }^{b)}$ \\
\hline Age (yr) & $61.8 \pm 13.4$ & $55.3 \pm 13.0$ & $<0.001$ & - & - \\
\hline Parity & $3.0 \pm 1.8$ & $2.6 \pm 1.6$ & 0.005 & - & - \\
\hline $\mathrm{Qmax}(\mathrm{mL} / \mathrm{sec})$ & $20.9 \pm 11.3$ & $19.2 \pm 8.5$ & 0.38 & $2.00(0.18-3.81)$ & 0.03 \\
\hline Voided volume (mL) & $245 \pm 129$ & $281 \pm 119$ & 0.004 & $-25.2(-49.0$ to -1.4$)$ & 0.04 \\
\hline Postvoid residual (mL) & $77 \pm 64$ & $70 \pm 59$ & 0.08 & $5.4(-6.6$ to 17.4$)$ & 0.38 \\
\hline Voiding time (sec) & $54.8 \pm 78.0$ & $56.2 \pm 52.2$ & 0.001 & $0.24(-22.5$ to 11.8$)$ & 0.98 \\
\hline Strong desire to void (mL) & $233 \pm 102$ & $242 \pm 70$ & 0.04 & $-5.0(-20.5$ to 10.5$)$ & 0.53 \\
\hline $\operatorname{PdetQmax}\left(\mathrm{cm} \mathrm{H}_{2} \mathrm{O}\right)$ & $35.6 \pm 21.9$ & $31.3 \pm 19.0$ & 0.04 & $6.0(1.9-10.1)$ & 0.004 \\
\hline $\operatorname{MUCP}\left(\mathrm{cm} \mathrm{H}_{2} \mathrm{O}\right)$ & $63.3 \pm 29.5$ & $73.3 \pm 32.2$ & 0.002 & $-2.0(-7.5$ to 3.4$)$ & 0.47 \\
\hline Functional profile length $(\mathrm{cm})$ & $3.1 \pm 0.8$ & $3.1 \pm 0.9$ & 0.98 & $-0.01(-0.18$ to 0.17$)$ & 0.95 \\
\hline PTR at MUP (\%) & $89.8 \pm 29.8$ & $95.4 \pm 31.4$ & 0.08 & $-5.1(-11.4$ to 1.1$)$ & 0.11 \\
\hline Detrusor overactivity & $44(35)$ & $129(26)$ & 0.053 & $1.4(0.9-2.2)$ & 0.12 \\
\hline Bladder oversensitivity & $101(80)$ & $387(78)$ & 0.71 & $1.0(0.6-1.7)$ & 0.93 \\
\hline Urodynamic stress incontinence & $69(54)$ & $165(33)$ & $<0.001$ & $2.1(1.4-3.1)$ & 0.001 \\
\hline Functional $\mathrm{BOO}^{\mathrm{c})}$ & $25(22)$ & $91(21)$ & 0.95 & $1.06(0.64-1.79)$ & 0.80 \\
\hline Pad weight (g) & $16.8 \pm 30.7$ & $3.7 \pm 14.9$ & $<0.001$ & $11.7(7.9-15.5)$ & $<0.001$ \\
\hline BOOI & $-6.6 \pm 2.7$ & $-8.2 \pm 1.3$ & 0.69 & $2.5(-3.2$ to 8.2$)$ & 0.38 \\
\hline Bladder contractility index & $141.2 \pm 63.4$ & $129.8 \pm 46.7$ & 0.21 & $14.8(4.1-25.4)$ & 0.007 \\
\hline
\end{tabular}

Values are expressed as the mean \pm standard deviation or number (\%) unless otherwise indicated.

$\mathrm{OAB}$, overactive bladder syndrome; OR, odds ratio; CI, confidence interval; Qmax, maximal flow rate; PdetQmax, detrusor pressure at maximal flow during voiding cystometry; MUCP, maximal urethral closure pressure; PTR, pressure transmission ratio; MUP, maximal urethral pressure; BOO, bladder outlet obstruction; BOOI, bladder outlet obstruction index.

${ }^{a)}$ By the Wilcoxon rank-sum test or chi-square test. ${ }^{\text {b) }}$ Age and parity were significantly different between the OAB-wet and OAB-dry groups. The coefficient or odds ratio of $\mathrm{OAB}$-wet $(\mathrm{OAB}$-wet $=1 ; \mathrm{OAB}$-dry $=0)$ is derived from linear or logistic regression analysis of the value in each variable adjusted for age and parity to reveal the impact of OAB-wet on each variable, compared with OAB-dry. ${ }^{c}$ Only 539 cases $(\mathrm{OAB}$-wet, $\mathrm{n}=115$; OAB-dry, $\mathrm{n}=424$ ) had measurable PdetQmax data. 
Table 2. Comparisons of the bladder diary parameters between the OAB-wet and OAB-dry groups $(n=623)$

\begin{tabular}{|c|c|c|c|c|c|}
\hline Variable & $\begin{array}{l}\text { OAB-wet } \\
(\mathrm{n}=127)\end{array}$ & $\begin{array}{l}\text { OAB-dry } \\
(n=496)\end{array}$ & P-value ${ }^{a)}$ & $\begin{array}{c}\text { Coefficient }(95 \% \text { CI }) \text { of } \\
\text { OAB-wet }{ }^{\text {b) }}\end{array}$ & P-value ${ }^{\text {b) }}$ \\
\hline DVVmax (72 hr) & $359 \pm 161$ & $356 \pm 166$ & 0.68 & $5.8(-26.8$ to 38.3$)$ & 0.73 \\
\hline Urgency episodes (72 hr) & $11.5 \pm 11.1$ & $7.2 \pm 11.8$ & $<0.001$ & $4.6(2.3-6.9)$ & $<0.001$ \\
\hline Incontinence episodes (72 hr) & $6.4 \pm 7.0$ & $0 \pm 0$ & $<0.001$ & $6.3(5.7-6.9)$ & $<0.001$ \\
\hline Daytime frequency (72 hr) & $29.1 \pm 10.6$ & $31.5 \pm 16.3$ & 0.39 & $-1.2(-4.2$ to 1.8$)$ & 0.42 \\
\hline Nocturia (72 hr) & $4.6 \pm 4.4$ & $4.7 \pm 4.0$ & 0.38 & $-0.3(-1.1$ to 0.5$)$ & 0.49 \\
\hline Total voided volume (mL/72 hr) & $5,490 \pm 2,478$ & $5,487 \pm 2,067$ & 0.51 & $51.3(-378.4$ to 481.1$)$ & 0.82 \\
\hline Total water intake (mL/72 hr) & $4,845 \pm 2,063$ & $5,039 \pm 1,984$ & 0.29 & $-105.8(-502.7$ to 291.10$)$ & 0.60 \\
\hline
\end{tabular}

Values are expressed as the mean \pm standard deviation unless otherwise indicated.

$\mathrm{OAB}$, overactive bladder syndrome; CI, confidence interval; DVVmax, maximal daytime voided volume excluding the morning void derived from 3-day bladder diaries.

${ }^{a}$ Wilcoxon rank-sum test or chi-square test. $\left.{ }^{b}\right)$ The coefficient of $O A B$-wet $(\mathrm{OAB}$-wet $=1$; $\mathrm{OAB}$-dry $=0)$ is derived from linear regression analysis of the value in each variable adjusted for age and parity.

Table 3. Factors predicting women with $\mathrm{OAB}$-wet using univariate and multivariable logistic regression

\begin{tabular}{|c|c|c|c|c|c|c|}
\hline \multirow{2}{*}{ Variable } & \multicolumn{2}{|l|}{ Univariate } & \multicolumn{2}{|c|}{ Multivariate $^{\mathrm{a})}$, model 1} & \multicolumn{2}{|c|}{ Multivariate $^{\mathrm{a})}$, model 2} \\
\hline & Odds ratio (95\% CI) & $\mathrm{P}$-value & Odds ratio $(95 \% \mathrm{CI})$ & P-value ${ }^{a)}$ & Odds ratio $(95 \% \mathrm{CI})$ & P-value ${ }^{\text {a) }}$ \\
\hline Age & $1.04(1.02-1.060)$ & $<0.001$ & $1.05(1.03-1.08)$ & $<0.001$ & $1.05(1.03-1.08)$ & $<0.001$ \\
\hline Parity & $1.02(1.06-1.34)$ & 0.004 & $0.92(0.77-1.10)$ & 0.36 & $0.92(0.77-1.10)$ & 0.37 \\
\hline Qmax & $1.02(1.00-1.04)$ & 0.07 & $1.06(1.03-1.09)$ & $<0.001$ & - & - \\
\hline Voided volume & $0.997(0.996-0.999)$ & 0.003 & $0.996(0.993-0.998)$ & 0.001 & $0.995(0.993-0.998)$ & $<0.001$ \\
\hline PdetQmax & $1.01(1.00-1.02)$ & 0.04 & $1.02(1.01-1.03)$ & 0.003 & - & - \\
\hline Urodynamic stress incontinence & $2.39(1.61-3.55)$ & $<0.001$ & $1.78(1.13-2.82)$ & 0.01 & $1.75(1.11-1.05)$ & 0.02 \\
\hline Urgency episodes & $1.03(1.01-1.04)$ & $<0.001$ & $1.04(1.02-1.05)$ & $<0.001$ & $1.04(1.02-1.05)$ & $<0.001$ \\
\hline Bladder contractility index ${ }^{\mathrm{b})}$ & $1.004(1.000-1.008)$ & 0.04 & - & - & $1.012(1.007-1.018)$ & $<0.001$ \\
\hline
\end{tabular}

Model 1: Using age, parity, and the other statistically significant adjusted variables shown in Tables 1 and 2, but not using bladder contractility index as a variable, a multivariable logistic regression was performed to predict OAB-wet; model 2: Bladder contractility index was included as a variable for multivariable logistic regression to predict OAB-wet, instead of using Qmax and PdetQmax as variables.

$\mathrm{OAB}$, overactive bladder syndrome; $\mathrm{CI}$, confidence interval; Qmax, maximal flow rate; PdetQmax, detrusor pressure at maximal flow during voiding cystometry.

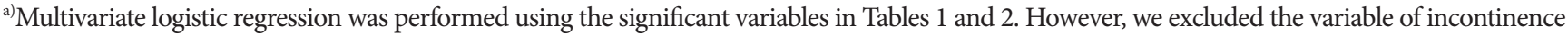
episodes in the model because incontinence episodes $>0$ predicts OAB-wet perfectly, and women with incontinence episodes $>0$ were defined to be in the OAB-wet group. ${ }^{\mathrm{b})}$ Bladder contractility index $=$ PdetQmax $+5 \times$ Qmax.

$\operatorname{dex}(\mathrm{OR}, 1.012 ; \mathrm{P}<0.0001)$ was found to be an independent predictor for $\mathrm{OAB}$-wet (Table 3).

\section{DISCUSSION}

Compared with OAB-dry, a smaller voided volume (OR, 0.996) and higher urgency episodes $(\mathrm{OR}, 1.04)$ were found to be predictors of OAB-wet (Table 3). Al-Zahrani and Gajewski [26] reported that as overactive bladder symptoms increase in severity, female patients tend to have a smaller bladder capacity. Urgency is the core symptom of female OAB [27], and Giarenis et al. [28] found a negative correlation between urgency episodes and bladder capacity in women with idiopathic DO. Thus, together with our findings, the speculation of $\mathrm{OAB}$-wet as a severe form of $\mathrm{OAB}$ seems reasonable.

Cho et al. [29] reported similar Qmax (mean: $15.3 \mathrm{~mL} / \mathrm{sec}$ vs. $15.0 \mathrm{~mL} / \mathrm{sec}, \mathrm{P}=0.759$ ) and PdetQmax (mean: $31.0 \mathrm{~cm} \mathrm{H}_{2} \mathrm{O}$ vs. $31.4 \mathrm{~cm} \mathrm{H}_{2} \mathrm{O}, \mathrm{P}=0.862$ ) between the $\mathrm{OAB}$-dry and OAB-wet patients. In our study, high $\mathrm{Qmax}(\mathrm{OR}, 1.06)$ and high PdetQmax $(\mathrm{OR}, 1.01)$ were identified as novel predictors for OAB-wet (Table 
3). Furthermore, bladder contractility index (i.e., = PdetQmax $+5 \times \mathrm{Qmax})[25](\mathrm{OR}, 1.012, \mathrm{P}<0.001)$ is an independent predictor for OAB-wet (Table 3). Thus, our findings of high Qmax, high PdetQmax, and high bladder contractility index as predictors of $\mathrm{OAB}$-wet may hint that the bladder contractility is better for OAB-wet, compared with OAB-dry.

Old age (OR, 1.04) is another predictor for OAB-wet (Table 3). Chen et al. [4] reported that the prevalence of OAB-wet increased with advancing age. Tyagi et al. [30] reported a significant association between $\mathrm{OAB}$ symptoms and age (OR,1.12). Hung et al. [27] also reported that women with OAB-wet had a greater average age.

In our study, USI was a predictor for OAB-wet, and women with $\mathrm{OAB}$-wet had a higher incidence of coexistent USI, vs. OAB-dry (54.3\% vs. 33.5\%, $\mathrm{P}<0.001)$ (Table 1). From the ambulatory urodynamic monitoring data of Dokmeci et al. [31], the rate of stress urinary incontinence in $\mathrm{OAB}$-wet also had a trend to be higher than OAB-dry ( $72.5 \%$ vs. $52.8 \%, \mathrm{P}=0.075)$. From the above, if the clinical works for treating $\mathrm{OAB}$-wet resulted in poor therapeutic response, then combined treatment for the coexistence of USI might be considered in clinical practice.

Nowadays, treatments for OAB-wet vs. OAB-dry patients are nearly the same [9]. However, from our results, $O A B$-wet women have different clinical presentations, such as greater severity in symptoms, greater bladder contractility and higher coexistent USI rate, compared with OAB-dry (Table 3). Thus, pretreatment assessment or treatment strategies might be different for $\mathrm{OAB}$ wet vs. OAB-dry. For example, urodynamic studies to unmask USI might be indicated for OAB-wet women with poor response to pharmacotherapy [32]; higher starting dose for the treatment of $\mathrm{OAB}$ might be more suitable for $\mathrm{OAB}$-wet; for the indication of intravesical injection of onabotulinumtoxin $\mathrm{A}[10,32]$, OABwet patients should be more suitable than OAB-dry [10]. Future prospective clinical studies should be performed to find the most suitable treatment strategy for OAB-wet vs. OAB-dry patients.

The retrospective design of this study was a limitation; however, the large sample size should make our data reliable. Besides, we do not have the posttreatment data. Further studies may be performed to elucidate post-treatment differences between $\mathrm{OAB}$-dry and OAB-wet. In addition, we do not have long-term follow-up data; future long-term follow-up studies may be performed to clarify the relationship between OAB-dry and OAB-wet.

In conclusion, a smaller bladder capacity and more frequent urgency episodes were predictors of OAB-wet, and the above findings indicate that $\mathrm{OAB}$-wet and $\mathrm{OAB}$-dry might be a continuum of OAB. Old age, high Qmax, high PdetQmax, and USI were also independent predictors for $\mathrm{OAB}$-wet, and the above results indicate that $\mathrm{OAB}$-wet and $\mathrm{OAB}$-dry have partially different clinical and urodynamic features. Further studies may be performed to elucidate whether different treatment strategies between $\mathrm{OAB}$-dry and $\mathrm{OAB}$-wet could improve treatment efficacy.

\section{AUTHOR CONTRIBUTION STATEMENT}

- Full access to all the data in the study and takes responsibility for the integrity of the data and the accuracy of the data analysis: $S M H, H H L$

-Study concept and design: $H H L$

- Acquisition of data: TCC, $\mathrm{CHC}$

- Analysis and interpretation of data: $S M H$

- Drafting of the manuscript: $S M H, P C W$

- Critical revision of the manuscript for important intellectual content: $H H L$

- Statistical analysis: $S M H$

- Obtained funding: $H H L$

- Administrative, technical, or material support: $H H L$

- Study supervision: $H H L$

\section{REFERENCES}

1. Haylen BT, de Ridder D, Freeman RM, Swift SE, Berghmans B, Lee J, et al. An International Urogynecological Association (IUGA)/International Continence Society (ICS) joint report on the terminology for female pelvic floor dysfunction. Neurourol Urodyn 2010; 29:4-20.

2. Anger JT, Le TX, Nissim HA, Rogo-Gupta L, Rashid R, Behniwal A, et al. How dry is "OAB-dry"? Perspectives from patients and physician experts. J Urol 2012;188:1811-5.

3. Tubaro A. Defining overactive bladder: epidemiology and burden of disease. Urology 2004;64(6 Suppl 1):2-6.

4. Chen YC, Ng SC, Chen SL, Huang YH, Hu SW, Chen GD. Overactive bladder in Taiwanese women: re-analysis of epidemiological database of community from 1999 to 2001. Neurourol Urodyn 2012; 31:56-9.

5. Kuo HC, Liu HT, Chancellor MB. Urinary nerve growth factor is a better biomarker than detrusor wall thickness for the assessment of overactive bladder with incontinence. Neurourol Urodyn 2010;29: 482-7.

6. Hsiao SM, Lin HH, Kuo HC. The role of serum C-reactive protein 
in women with lower urinary tract symptoms. Int Urogynecol J 2012;23:935-40.

7. Hashim $\mathrm{H}$, Abrams P. Is the bladder a reliable witness for predicting detrusor overactivity? J Urol 2006;175:191-4.

8. Al-Ghazo MA, Ghalayini IF, Al-Azab R, Hani OB, Matani YS, Haddad Y. Urodynamic detrusor overactivity in patients with overactive bladder symptoms. Int Neurourol J 2011;15:48-54.

9. Hsiao SM, Lin HH. Medical treatment of female overactive bladder syndrome and treatment-related effects. J Formos Med Assoc 2018; 117:871-8.

10. Hsiao SM, Lin HH, Kuo HC. Factors associated with therapeutic efficacy of intravesical onabotulinumtoxinA injection for overactive bladder syndrome. PLoS One 2016;11:e0147137.

11. Balzarro M, Rubilotta E, Braga A, Bassi S, Processali T, Artibani W, et al. OnabotulinumtoxinA detrusor injection improves female sexual function in women with overactive bladder wet syndrome. Eur J Obstet Gynecol Reprod Biol 2018;225:228-31.

12. Hsiao SM, Lin HH, Kuo HC. Factors associated with a better therapeutic effect of solifenacin in patients with overactive bladder syndrome. Neurourol Urodyn 2014;33:331-4.

13. Nixon A, Colman S, Sabounjian L, Sandage B, Schwiderski UE, Staskin DR, et al. A validated patient reported measure of urinary urgency severity in overactive bladder for use in clinical trials. J Urol 2005;174:604-7.

14. Hsiao SM, Su TC, Chen CH, Chang TC, Lin HH. Autonomic dysfunction and arterial stiffness in female overactive bladder patients and antimuscarinics related effects. Maturitas 2014;79:65-9.

15. Hsiao SM, Liao SC, Chen CH, Chang TC, Lin HH. Psychometric assessment of female overactive bladder syndrome and antimuscarinics-related effects. Maturitas 2014;79:428-34.

16. Stewart WF, Van Rooyen JB, Cundiff GW, Abrams P, Herzog AR, Corey R, et al. Prevalence and burden of overactive bladder in the United States. World J Urol 2003;20:327-36.

17. Sand PK, Ostergard DR, editors. Urodynamics and the evaluation of female incontinence: a practical guide. London: Springer-Verlag; 1995.

18. Wu WY, Sheu BC, Lin HH. Comparison of 20-minute pad test versus 1-hour pad test in women with stress urinary incontinence. Urology 2006;68:764-8.

19. Wu WY, Sheu BC, Lin HH. Twenty-minute pad test: comparison of infusion of $250 \mathrm{ml}$ of water with strong-desire amount in the bladder in women with stress urinary incontinence. Eur J Obstet Gynecol Reprod Biol 2008;136:121-5.
20. Hsiao SM, Lin HH, Kuo HC. Videourodynamicstudies of women with voiding dysfunction. Sci Rep 2017;7:6845.

21. Hsiao SM, Hsiao CF, Chen CH, Chang TC, Wu WY, Lin HH. Evaluation of bladder diary parameters based on correlation with the volume at strong desire to void in filling cystometry. PLoS One 2013;8:e69946.

22. Chen CH, Hsiao SM, Chang TC, Wu WY, Lin HH. Clinical and urodynamic effects of baclofen in women with functional bladder outlet obstruction: preliminary report. J Obstet Gynaecol Res 2016; 42:560-5.

23. Chassagne S, Bernier PA, Haab F, Roehrborn CG, Reisch JS, Zimmern PE. Proposed cutoff values to define bladder outlet obstruction in women. Urology 1998;51:408-11.

24. Altman DG. Practical statistics for medical research. London: Chapman \& Hall; 1991.

25. Abrams P. Bladder outlet obstruction index, bladder contractility index and bladder voiding efficiency: three simple indices to define bladder voiding function. BJU Int 1999;84:14-5.

26. Al-Zahrani AA, Gajewski J. Urodynamic findings in women with refractory overactive bladder symptoms. Int J Urol 2016;23:75-9.

27. Hung MJ, Ho ES, Shen PS, Sun MJ, Lin AT, Chen GD, et al. Urgency is the core symptom of female overactive bladder syndrome, as demonstrated by a statistical analysis. J Urol 2006;176:636-40.

28. Giarenis I, Zacchè M, Robinson D, Cardozo L. Is there any association between urodynamic variables and severity of overactive bladder in women with idiopathic detrusor overactivity? Neurourol Urodyn 2017;36:780-3.

29. Cho KJ, Kim HS, Koh JS, Kim JC. Evaluation of female overactive bladder using urodynamics: relationship with female voiding dysfunction. Int Braz J Urol 2015;41:722-8.

30. Tyagi P, Tyagi V, Qu X, Lin HT, Kuo HC, Chuang YC, et al. Association of inflammaging (inflammation + aging) with higher prevalence of $\mathrm{OAB}$ in elderly population. Int Urol Nephrol 2014;46:8717.

31. Dokmeci F, Cetinkaya SE, Seval MM, Dai O. Ambulatory urodynamic monitoring of women with overactive bladder syndrome during single voiding cycle. Eur J Obstet Gynecol Reprod Biol 2017; 212:126-31.

32. Giannantoni A, Carbone A, Carone R, Cervigni M, Del Popolo G, Agrò $\mathrm{EF}$, et al. Real-life clinical practice of onabotulinum toxin $\mathrm{A}$ intravesical injections for overactive bladder wet: an Italian consensus statement. World J Urol 2017;35:299-306. 